\title{
Effect of Plocamium cartilagineum aegypticus on Boophilus annulatus
}

\author{
Rania A. Abd El-Wahab \\ Plant protection research institute, agriculture research center
}

\begin{abstract}
Halogenated monoterpenes isolated from the red alga Plocamium cartilagineum aegypticus, proved their efficacy as acaricide. Both of Violacene and Mertensene, were adulticides with $\mathbf{L C}_{50}$ 's, $340.56 \mathrm{ppm}$ and $759.23 \mathrm{ppm}$, respectively, against the cattle tick; Boophilus annulatus adult females. Moreover, they can be used as ovicides. Violacene and Mertensene caused reduction in the hatchability by $96.77 \%$ and $95 \%$ respectively. Clinico-pathological studies were carried out and showed that Plocamium extract is safe to the host and none-target animals.
\end{abstract}

Seaweeds of the family Plocamiaceae, (order Gigartinales) are distributed world-wide. The largest variety of halogenated monoterpenes has been isolated from Plocamium cartilagineum, the most cosmopolitan Plocamium species, with collections ranging from such diverse locations as the Pacific coasts of North America and Australia, the Mediterranean, the Isle of Wight and the inhospitable Janus Island of Antarctica. The insecticidal and acaricidal activities of polyhalogenated monoterpenes from $P$. cartilagineum have been demonstrated against various agricultural pests but concerning the evaluation of its efficacy as acaricide against cattle ticks, there aren't available researches in that side. Although, ticks are very important ectoparasite of domestic animals, (Roberts and Janovy, 2005). The cattle tick, Boophilus annulatus(Say, 1821) not only affected production of cattle when found in large numbers, but also the vector of many viral and rickettsial diseases. There are many classes of acaricides were used to control ticks including; chlorinated hydrocarbons (Foil et al., 2004); pyrethroids (Rosario-Cruz et al., 2005); organophosphates (Miller et al., 2005); carbaryl (Andrew et al., 2005); formamidines (Ducornez et al., 2005) and avermectins (George and Davey, 2004). B.annulatus gained resistance to most of these compounds, so we faced another problem beside the main one which concerning environment pollution with more pesticides. Accordingly, the need of new pesticides is increasing and being urgently.

The aim of the present study is to evaluate Plocamium cartilagineum aegypticus halogenated monoterpenes as novel and environmentally safe acaricide against $B$. annulatus beside determination of changes of some biochemical aspects through the direct treatement of the host animal of these ticks.

\section{Materials and methods}

Alga Extract. Plocamium cartilagineum (Linnaeus) Dixon was collected from the Mediterranean sea coast of Egypt. The dried alga $(500 \mathrm{~g})$ as extracted with acetone at room temperature to give a dark residue ( $40 \mathrm{~g}$ ). This extract was chromatographed on silica gel. The fraction eluted with hexane: EtOAc (95: 5) was further separated by filtration chromatography and Si-gel chromatography to yield Mertensene. The fraction eluted with hexane: EtOAc (4:1) was further separated by filtration chromatography to give Violacene .

Analysis and Identification. IR spectra were obtained with a spectrometer in $\mathrm{CHCl}_{3}$ solutions. ${ }^{1} \mathrm{H}$ NMR and ${ }^{13} \mathrm{C}$ NMR spectra were measured employing a Bruker AMX 300 instrument operating at $300 \mathrm{MHz}$ for $1 \mathrm{H}$ NMR and at $75.13 \mathrm{MHz}$ for ${ }^{13} \mathrm{C}$ NMR, using TMS as internal standard. HPLC separations were performed with a Merck-Hitachi L-6200 Intelligent pump and a L-4000 UV detector.(Argandoña et al., 2000). The gel filtration column used hexane-MeOH-CHCl $(2: 1: 1)$ as eluent solvent. The spray reagent for TLC was $\mathrm{H}_{2} \mathrm{SO}_{4}$ : $\mathrm{MeOH}$ (1:9).

Tick Rearing. Adult Boophilus annulatus were collected from naturally infested cattle. Female ticks were selected and maintained in the laboratory at $26^{\circ} \mathrm{C}$ and $70 \% \mathrm{RH}$ in test tubes for laying eggs.After hatching of the eggs, tick larva were fed on healthy 1-3 month-old rabbits. Female ticks were collected from the experimentally infested cattles and transferred to 
the laboratory to perform the subsequent experiment within 3-4 hours

Experiment on Ticks. Regarding the concentration-response bioassay ,studying the acaricidal property of halogenated monoterpenes isolated from the red alga Plocamium cartilagineum was performed. Tested concentrations of each active ingredients were triple replicated and the bioassay was done in vitro at $\left(25 \pm 2^{\circ} \mathrm{C}\right.$ and $\left.75 \% \mathrm{RH}\right)$. Ten ticks per replicate were placed in a clean dry Petri dish with a filter paper. Disc of Whatman No.1 filter paper measuring $62.63 \mathrm{~cm}^{2}$ surface areas, impregnated uniformly with the used concentration of each active ingredient on the bottom. The control groups were treated with distilled water. Ticks were considered alive if they exhibited normal behavior when breathed upon or physically stimulated with a wooden dowels. Readings were taken after $30 \mathrm{~min}$. of contact treatments. Mortality percentages were determined and corrected by using Abott's formula (1925)and they were statically analyzed according to (Finney, 1971) to estimate $\mathrm{LC}_{50}, \mathrm{LC}_{90}$ and slope values.

Experiment on Tick's Eggs. After sterilization of adult tick by immersing in ethanol $70 \%$ for 3 sec.Still alive females after each treatment were transferred to sterile Petri dishes to lay egg in $25^{\circ} \mathrm{C}$ and $70 \%$ RH.Eggs $(n=100)$ were placed in Petri dishes $(50 \mathrm{~mm}$ diam.) containing filter paper that was previously sprayed with $0.5 \mathrm{ml}$ of the two active ingredients. Eggs hatchability was noticed throughout 30 days after treatments.

Effect of Violacene on ticks' host. Clinicopathological tests were carried out under laboratory conditions to evaluate the effects of Violacene on rabbits. Animals were weighted before and after treatments. Serum biochemical analysis including alanine aminotransferase (ALT), asprtate aminotransferase(AST) according to (Waner and Nyska, 1991), glucose, cholesterol, uric acid (Morin and Prox, 2001) and creatinine were done.

\section{Results and Discussion}

The concentration-response bioassay revealed the acaricidal efficacy of halogenated monoterpenes on engorged $B$. annulatus females, Table (1).Violacene $\mathrm{LC}_{50}$ (340.56 ppm) was higher than that of Mertensene LC $_{50}(759.23$ ppm). On basis of slope values, Violacene had the steepest toxicity line (slope 2.1), whereas Mertensene had the flattest one (slope $=1.5$ ). Considering the $\mathrm{LC}_{90} / \mathrm{LC}_{50}$ ratio, (Table 1), Violacene which possessed the highest slope of toxicity line recorded the lowest ratio(2.38), whereas Mertensene, had the lowest slope, recorded the highest ratio (15.11).Eggs treatments were shown (Table 2). Reduction of hatchability percentages were 96.77 and 95 of Violacene, Mertensene, respectively, than control. Previous data mean that halogenated monoterpenes can be used as ovicides as equal as adulticides with highly percentages in the hatchability reduction even more than used chemical pesticides but with more safe use.

Concerning clinical pathological studies which depended on the direct treatment by injection with Violacene, serum biochemical analysis showed that no highly differences between control and treated animals at all tested aspects. ALA, AST, glucose, cholesterol, uric acid and creatinine values were in the same trend as control values with slight differences .All of these results proved its safety to mammals. In addition, there was so noticed increase in the weight in the treated animals in comparable with control.

The use of botanical pesticides is the most new option to control ticks in the limits of biological control which can move at two aspects in the same time. The first, avoiding environment pollution with chemicals and the second aspect is depending on the safety of the user and the exposure at the same time with effectively result against parasites. There are several researchers work in that trend such as, Abdel Shafy and Zayed, (2002), they studied the effect of Azal F at concentrations of 1.6 to $12.8 \%$, against the Egyptian tick, Hyalomma anatolicum excavatum (Kock, 1844). It induced a significant increased in mortality rates of unfed adults reaching $100 \%$ on $15^{\text {th }}$ day post-treatment. Moreover, Abel-Shafy and Soliman, (2004) tested the effect of five essential oils belonging to the Family: Labiatidae: peppermint(Mentha piperita); spearmint (Mentha viridis); marjoram (Marjorana hortensis); lavender (Lavandula officinalis) and sweet basil (Ocimum basilicum) against fed females of the cattle tick $B$. annulatus. Dipping technique was used for 30 seconds, and the mortality was recorded after 3 days post-treatment. All experiential oils had effects on fed females, oil treatments (0.5$5 \%$ )caused mortality rates of 6.7 to $98.3 \%, 5.6$ to $40 \%$; 56.7 to $90 \%$; 67 to $93.3 \%$; and 26.7 to $98 \%$ with the previous oils, respectively. The $\mathrm{LC}_{50}$ values were $2.85,10.57,0.52,3.25$, and $1.01 \%$, respectively. 
Table (1): Acaricidal efficacy of Plocamium cartileganium halogenated monoterpenes on engorged Boophilus annulatus females.

\begin{tabular}{|c|c|c|c|c|c|c|c|c|c|c|}
\hline \multirow{2}{*}{$\begin{array}{l}\text { Halogenated } \\
\text { Monoterpenes }\end{array}$} & \multicolumn{3}{|c|}{$\mathbf{L C}_{50}(\mathbf{p p m})$} & \multicolumn{3}{|c|}{$\mathrm{LC}_{90}(\mathbf{p p m})$} & \multirow[t]{2}{*}{ Sope } & \multirow{2}{*}{$\begin{array}{l}\text { Toxicity } \\
\text { Index }\end{array}$} & \multirow{2}{*}{$\begin{array}{l}\text { Relative } \\
\text { Potency }\end{array}$} & \multirow{2}{*}{$\begin{array}{l}\mathbf{L C}_{90} / \\
\text { LC }_{50} \\
\text { Ratio }\end{array}$} \\
\hline & Main & U.L & L.L & Main & U.L & L.L & & & & \\
\hline Violacene & 340.56 & 408.68 & 283.80 & 810.32 & 1062.92 & 542.36 & 2.1 & 100 & 2.34 & 2.38 \\
\hline Mertensene & 759.23 & 972.38 & 675.27 & 11472.33 & 16061.26 & 8194.52 & 1.5 & 44.86 & ------ & 15.11 \\
\hline
\end{tabular}

Table (2): Efficacy of Plocamium cartileganium halogenated monoterpenes on Boophilus annulatus eggs.

\begin{tabular}{lcccc}
\hline $\begin{array}{l}\text { Halogenated } \\
\text { Monoterpenes }\end{array}$ & Total Eggs & Hatched Eggs & \%Hatchability & $\begin{array}{c}\text { \%Reduction of } \\
\text { Hatchability }\end{array}$ \\
\hline Violacene & 102 & 20 & 19.61 & 96.77 \\
Mertensene & 143 & 31 & 21.78 & 95 \\
Control & 700 & 620 & 88.57 & --- \\
\hline
\end{tabular}

Table (3): Serum biochemical analysis of rabbits injected with Violacene.

\begin{tabular}{lcccccc}
\hline Rabbits & $\begin{array}{c}\text { AST } \\
\mathbf{U} / \mathbf{L}\end{array}$ & $\begin{array}{c}\text { ALT } \\
\mathbf{U} / \mathbf{L}\end{array}$ & $\begin{array}{c}\text { Glucose } \\
\mathbf{m g} / \mathbf{d l}\end{array}$ & $\begin{array}{c}\text { Cholesterol } \\
\mathbf{m g} / \mathbf{d l}\end{array}$ & $\begin{array}{c}\text { Uric A } \\
\mathbf{m g} / \mathbf{d l}\end{array}$ & $\begin{array}{c}\text { Creatinine } \\
\mathbf{m g} / \mathbf{d l}\end{array}$ \\
\hline Control & $15 \pm 0.23$ & $18 \pm 0.14$ & $20 \pm 1.24$ & $75 \pm 0.79$ & $2.8 \pm 0.64$ & $0.4 \pm 0.49$ \\
Violacene & $21 \pm 0.34$ & $25 \pm 0.58$ & $12 \pm 0.31$ & $100 \pm 0.25$ & $3.6 \pm 0.18$ & $0.8 \pm 0.36$ \\
\hline
\end{tabular}

The use of alga extracts is the newest tool in biological control of ticks, especially red algae which showed great efficacy to be insecticide and acaricide beside its effect as medicine. Afolayan et al., (2009) examined the antiplasmodial organic extracts of the endemic marine red alga Plocamium cornutum (Turner) Harvey as an antimalarial. Two new and three known halogenated monoterpenes were isolated and their structures determined by standard spectroscopic techniques. The 3,7-dimethyl-3,4dichloro-octa-1,5,7-triene skeleton is common to all five compounds. Interestingly, compounds bearing the 7-dichloromethyl substituent showed significantly higher antiplasmodial activity toward a chloroquine sensitive strain of Plasmodium falciparum.

Natural marine products have recently become the focus of increased research interest, due to their potential pharmacological activities. Harden et al., (2009) found that Plocamium sp. extracts are nontoxic and effective virucidal agents that warrant further investigation to examine their potential role in the prevention of Herpes simplex virus types 1 and 2 (HSV-1, HSV-2) infections of humans. Therefore, Kim et al., (2007) have screened 50 varieties of marine seaweed and determined that the methanolic extracts from Plocamium telfairiae (PTE) which used to exhibit a cytotoxic effect against HT-29 human colon carcinoma cells. In this study, they report on the cytotoxic activity and mechanism of PTE-induced apoptosis in HT-29 cells. The treatment of HT-29 cells with various PTE concentrations resulted in the inhibition of growth and the induction of apoptosis in a dosedependent manner, as determined by the results of a 3-(4,5-dimethylthiazol-2-yl)-2,5-diphenyltetrazolium bromide reduction assay, a lactate dehydrogenase release assay, a morphological assay, and a colony formation assay. Interestingly, they also detected apoptotic bodies on Hoechst staining and attempted to determine whether the PTE-induced apoptosis involved the caspase pathway, using a caspase colorimetric assay. The activation of caspases and the specific proteolytic cleavage of poly (ADP-ribose) polymerase were detected over the course of apoptosis induction. Their results showed that PTE may function as a chemopreventive and/or chemotherapeutic agent in colon carcinoma cells via the reduction of cell viability and the induction of apoptosis. We can conclude that, these new active ingredients can be used safely to get good results in our treatments to control ticks infested various animals.

\section{References}

Abott, W. S. (1925): A method of computing effectiveness of an insecticide. J. Econ. Entomol.,18: 265-267.

Abdel Shafy S. and Zayed, A. A. (2002): In vitro acaricidal effect of plant extract of neem seed oil (Azadirachta indica) on egg, immature, andadult stages of Hyalomma anatolicum excavatum (Ixodoidea, Ixodidae). Vet. Parasitol., 16: 89-96.

Abel-Shafy, S. and Soliman, M. M. (2004): Toxicity of some essential oils on eggs, larvae and females of Boophilus annulatus (Acari, Ixodidae, Amblyommidae) infesting cattle in Egypt. Acarologia. XLIV: 23-30. 
Afolayan, A. F.; Mann, M. G.; Lategan, C.; Smith, P. J.; Bolton, J. J. and Beukes, D. R. (2009): Antiplasmodial halogenated monoterpenes from the marine red alga Plocamium cornutum. Photochem., 70(5):597-600.

Andrew, Y. L.; Davey, R. B. and George, J. E. (2005): Carbaryl resistance in Mexican strains of the southern cattle tick (Acari, Ixodidae). J.Med.Entomol., 98: 552-556.

Argandoña,V.; Del Pozo, T.; San-Martín, A. and Rovirosa, J. (2000): Insecticidal activity of Plocamium cartilagineum. monoterpenes. 2000. Bol. Soc. Chil. Qusm., 45 (3):10-13.

Ducornez, S.; Barre, N.; Miller, R. J. and GarineWichatitsky, M. D. (2005): Diagnosis of amitraz resistance in Boophilus microplus in New Caledonia with the modified larval packet test. Vet. Parasitol., 130:285-292.

Finney, D. J. (1971): Probit analysis, a statistical treatment of sigmoid response curve. Cambridge University Press.

Foil, L. D.; Coleman, P.; Eisler, M.; Fragoso-Sanchez, H.; Garcia-Vazques, Z.; Guerrero, F. D.; Jonsson, N. N.; Langstaff, I. G.; Li, A. Y. and Machila, N. (2004): Factors that influence the prevalence of acaricide resistance and tick-borne diseases. Vet. Parasitol., 125:163-181.

George, J. E. and Davey R. B. (2004): Therapeutic and Persistent Efficacy of a Single Application of Doramectin Applied Either as a Pour-on or Injection to Cattle Infested with Boophilus microplus (Acari, Ixodidae). J. Med. Entomol., 41:402-407.

Harden, E. A.; Falshaw, R.; Carnachan, S. M.; Kern, E. R. and Prichard, M. N. (2009): Virucidal activity of polysaccharide extracts from four algal species against herpes simplex virus. Antiviral Res., 83(3):282-289.

Hill, R. A. (2003): Marine natural products. Annu. Rep. Prog. Chem., Sect. B, 99:183-207.

Kim, J.; Yoon, M.; Cha, M.; Hwang, J.; Park, E.; Choi, S.; Park, H. and Hwang, Y. (2007): Methanolic Extracts of Plocamium telfairiae Induce Cytotoxicity and CaspaseDependent Apoptosis in HT-29 Human Colon Carcinoma Cells. J. Med. Food., 10(4): 587-593.

Miller, R. J.; Davey, R. B. and George, J. E. (2005): First report of organophosphate-resistant Boophilus microplus (Acari, Ixodidae)within the United states. Med. Entomol., 42: 912-917.

Morin, L. G. and Prox, J. (1973): Reduction of ferric phenanthroline-a procedure for determining serum uric acid. Am. J. Clin. Pathol., 60(5):691-4.

Roberts L. S. and Janovy J. (2005): Foundations of parasitology $7^{\text {th }}$ Ed. McGraw Hill. pp. 644-646

Rosario-Cruz, R.; Guerrero, F. D.; Miller, R. J.; Rodriguez-Vivas, R. I.; Dominguez-Garcia, D. I.; Cornel A . J.; Mernandez-Ortiz, R. and Goerge J. E. (2005): Roles played by esterase activity and by a sodium channel mutation involved in pyrethroids resistance in populations of Boophilus microplus (Acari: Ixodidae) collected from Yucatan, Mexico. J. Med. Entomol., 42:1020-1026.

Waner, T. and Nyska, A. (1991): The toxicological significance of decreased activities of blood alanine and aspartate aminotransferase. Vet. Res. Commu., 15: 73-78.

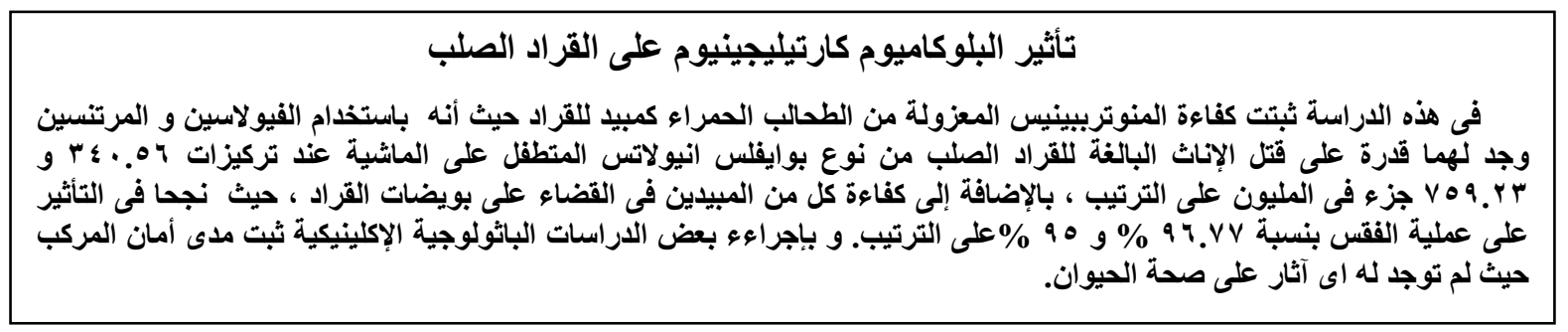

